\title{
FEDERALISMO FISCAL E FINANCIAMENTO DESCENTRALIZADO DO SUS: BALANÇO DE UMA DÉCADA EXPANDIDA
}

FISCAL FEDERALISM AND DECENTRALIZED SUS FUNDING: BALANCE OF AN EXPANDED DECADE

Luciana Dias de Lima ${ }^{1}$

Resumo O artigo aborda as relações entre o federalismo fiscal e o financiamento descentralizado do Sistema Único de Saúde (SUS), de 1990 até o início dos anos 2000, e indica os problemas do sistema tributário brasileiro, incapaz de compensar desequilíbrios fiscais entre as diferentes esferas de governo.

Palavras-chave federalismo fiscal; financiamento do Sistema Único de Saúde; descentralização da política de saúde.
Abstract The article deals with the relationships between fiscal federalism and the decentralized funding of the Single Health System (SUS), from 1990 to the early 2000's, and singles out the problems of the Brazilian tax system, which is unable to compensate for fiscal unbalance among the different spheres of the government.

Keywords fiscal federalism, funding of the Single Health System; decentralization of the health policy. 


\section{Introdução}

Embora o tema federalismo seja cada vez mais freqüente na produção científica brasileira e internacional, as discussões sobre os elos existentes entre determinados arranjos federativos e políticas específicas ainda são escassas. $\mathrm{O}$ artigo pretende contribuir para esse debate, abordando as repercussões do federalismo fiscal no financiamento descentralizado do Sistema Único de Saúde (SUS), no período de 1990 até o início dos anos 2000.

O recorte se justifica frente à importância adquirida pelos entes subnacionais de governo no sistema público de saúde brasileiro. A implantação dos princípios e diretrizes do SUS, válidos para todo o território nacional, depende das condições institucionais apresentadas pelas esferas municipais e estaduais no desempenho de responsabilidades e funções gestoras sobre a política de saúde, previstas na Constituição Federal de 1988 e regulamentação da saúde (leis e instrumentos normativos). Entre outras, a capacidade de financiamento em saúde desses governos é peça fundamental para a garantia do acesso universal e sem privilégios às ações e serviços do SUS, do cuidado integral compatível com as necessidades e demandas da população e realizado de acordo com padrões de qualidade reconhecidos.

No entanto, existe uma contradição intrínseca entre as imensas desigualdades socioeconômicas e territoriais que configuram a federação brasileira e o modelo pretendido na saúde, que coloca desafios para a adoção de mecanismos que compensem as diferenças nas condições materiais e financeiras das esferas subnacionais, através de um conjunto de relações fiscais e orçamentárias entre os governos.

Argumenta-se, nesse artigo, que os problemas associados ao federalismo fiscal no Brasil foram exacerbados pelo contexto político e econômico do período analisado e tiveram um impacto significativo no financiamento descentralizado do SUS. O modelo de federalismo fiscal, adotado sob os imperativos da política de estabilização econômica e contenção de gastos em saúde, acabou gerando constrangimentos e desequilíbrios federativos e não favoreceu a redistribuição de recursos a favor da redução das desigualdades nas condições de financiamento em saúde dos estados e municípios brasileiros. Essas características configuram um cenário bastante complexo onde as decisões sobre o financiamento do SUS foram efetuadas, com implicações significativas para o processo de descentralização em saúde.

Para a construção do argumento, realizou-se uma ampla revisão bibliográfica sobre os temas abordados, valendo-se, ainda, de pesquisa empírica realizada pela autora sobre as condições de financiamento em saúde dos governos subnacionais. Nesta pesquisa, os orçamentos municipais e estaduais são analisados, comparando-se e correlacionando-se os valores das re- 
ceitas públicas informadas pelos governos por meio do Sistema de Informações de Orçamentos Públicos em Saúde (Siops) no ano 2002.

Os resultados do estudo realizado são apresentados em duas partes. Primeiramente, procura-se identificar, a partir da discussão conceitual sobre as formas de organização de sistemas tributários em países federativos, alguns elementos para análise do caso brasileiro. Em seguida, faz-se um balanço dos efeitos das relações fiscais sobre o financiamento descentralizado do SUS, sob a ótica dos desequilíbrios orçamentários presentes considerando as distintas esferas de governo no Brasil. Por fim, busca-se discutir os significados das análises efetuadas para a compreensão do modelo de federalismo implantado e suas repercussões sobre o processo de descentralização da política de saúde, bem como sobre os problemas a serem enfrentados no âmbito de uma reforma tributária no país.

\section{Especificidade e dilemas dos sistemas tributários em países federativos}

As formas como se distribuem os poderes e se estabelecem as relações intergovernamentais, fiscais e orçamentárias, no âmbito das federações, configuram o federalismo fiscal. A importância dos estudos que enfatizam a dimensão fiscal é ressaltada por diversos autores. Affonso e Silva (1995) consideram que o principal mecanismo que garante a articulação dos interesses na federação são os fundos públicos. Eles possibilitam soldar o pacto federativo, contribuindo para a manutenção da unidade do Estado e do equilíbrio entre seus entes.

Watts (1996) afirma que a divisão da receita pública entre os distintos entes federativos é relevante por duas razões: os recursos financeiros permitem ou restringem os governos no exercício de seus encargos constitucionais; e o poder de captar e administrar receitas fiscais e de executar os dispêndios públicos são instrumentos poderosos de intervenção e regulação econômica do Estado.

Como arranjo institucional concreto, o federalismo fiscal é moldado por fatores econômicos, sociais, culturais e históricos, sendo, antes de tudo, resultado de escolhas políticas. Ele expressa o modo como os princípios de autonomia e interdependência são incorporados na gestão dos tributos, revela os valores federais que caracterizam uma dada sociedade e as formas como determinados conflitos são acomodados em um contexto histórico específico. Além disso, dada a sua relevância para a administração pública, influencia decisões importantes dos atores políticos com impacto significativo para as políticas públicas e as políticas de saúde em particular.

Não há um modelo teórico ideal, nem um padrão uniforme ditado pela prática para a configuração de sistemas tributários em países federativos. 
Para sua diferenciação, Watts (1996) recorre a dois elementos principais: o poder de tributar ou de arrecadar tributos e o poder de gastar, fatos que viabilizam o cumprimento das atribuições de governo. Geralmente decorrente da divisão de responsabilidades e funções, a repartição desses 'dois poderes' entre os governos subnacionais e o nacional caracteriza o modelo de federalismo fiscal implantado.

Há pelo menos duas décadas, observa-se nos países de organização federativa, uma tendência ao deslocamento de encargos e do poder de gasto sobre as políticas de corte social, do nível central para os níveis periféricos. A justificativa técnica, comumente utilizada, refere-se à necessidade de ampliar a eficiência administrativa no uso dos recursos. Argumenta-se que, quanto mais próximo das necessidades e demandas da população, maiores serão os benefícios atingidos e mais efetivos os mecanismos de controle sobre os gastos.

Entretanto, os movimentos pró-descentralização de responsabilidades e recursos também podem ser explicados pelo contexto em que se inserem. Dain (1995) ressalta que os ganhos de flexibilidade das esferas subnacionais em relação à definição sobre as prioridades, instrumentos e modalidades de gasto permitem às federações mais facilmente harmonizar a escassez de recursos e o corte de despesas que emanam da crise fiscal mundial a partir dos anos 70. O trade-off para as políticas sociais é que, gradativamente, o caráter universal consolidado em determinadas economias desenvolvidas e traduzido pela uniformidade de cobertura de serviços passa a ser "substituído como valor pela natureza mais representativa e democrática das escolhas feitas, não só quanto aos gastos a serem realizados, como em torno das prioridades a serem sacrificadas, no quadro de restrição de recursos" (Dain, 1995, p. 83).

Mas é preciso ponderar que a descentralização não necessariamente leva à contenção das despesas, pois a assunção de novas responsabilidades pelas esferas subnacionais podem gerar demandas e aumentar as necessidades de gasto. Banting e Corbett (2002) chamam atenção sobre esse aspecto ao analisarem os gastos em saúde apresentados por diferentes países federativos com graus de descentralização diversos sobre o sistema de saúde.

Por outro lado, nota-se que as transformações nas relações de poder sobre o gasto não foram acompanhadas na mesma intensidade pelas transferências das competências tributárias. Considera-se que os desequilíbrios fiscais entre as esferas de governo são intrínsecos e estão presentes em maior ou menor grau em qualquer federação.

Dois tipos de desequilíbrios podem ser verificados: os verticais, gerados pela elevada concentração de poder de tributação no ente federal, em contraposição às necessidades de gastos das esferas subnacionais pelos maiores encargos assumidos; e os horizontais, em razão de desigualdades 
socioeconômicas existentes entre os governos que determinam, por um lado, capacidades diferenciadas de provisão de serviços em sistemas de tributação comparáveis e, por outro, necessidades distintas de gastos públicos decorrentes de variações das necessidades e demandas da população.

Os sistemas de transferência intergovernamental de recursos tributários atuam na correção dos desequilíbrios verticais e horizontais. Vários são os fatores que interferem na adoção de determinados esquemas de repartição financeira, os critérios e condicionantes utilizados, assim como os governos envolvidos nos mecanismos de transferência implantados.

Em geral, quanto mais descentralizados os encargos e mais significativas as desigualdades inter-regionais, maiores são as necessidades de implantação de mecanismos de equalização fiscal para promover o equilíbrio horizontal da receita disponível2, pois as desigualdades horizontais têm efeito corrosivo sobre a coesão nacional. Ainda assim, as diferenças nos arranjos adotados refletem o grau de tolerância das sociedades em relação às desigualdades dos territórios político-administrativos. Sistemas mais ou menos complexos que visam graus distintos de igualdade podem ser adotados 3 .

Portanto, considera-se que problemas adicionais podem ser identificados na formatação de sistemas tributários em países federativos. Além dos requisitos clássicos - tributar com eqüidade e eficiência, adequar a distribuição de recursos via orçamento e executar o dispêndio visando a melhoria dos resultados alcançados - os sistemas tributários devem contemplar: a atribuição equilibrada de encargos entre esferas de governo, que exige o estabelecimento de normas e padrões nacionais, buscando estabelecer alguma homogeneidade nos serviços prestados; a divisão eficiente do sistema de competências tributárias, definido pelas funções de arrecadação e administração dos recursos; e a formatação de um sistema adequado de partilha, que envolve o conjunto de regras por meio das quais a receita tributária é distribuída entre os diferentes governos.

Essas três variáveis - distribuição de encargos formalmente regulamentados, definição de competências tributárias e sistema de partilha fiscal - são igualmente importantes para o entendimento dos diversos arranjos do federalismo fiscal, existindo estreitas relações de dependência entre elas.

No Brasil, pode-se dizer que a formatação do sistema tributário é ainda mais complexa se consideradas as especificidades que conformam sua organização federativa (Machado et al., 2007; Lima, 2007):

- a origem formal há mais de um século, porém o caráter ainda 'em construção' do federalismo brasileiro, em face dos longos períodos de autoritarismo centralizador na história do país e das transformações democráticas a partir dos anos 80; 
- o grande peso dos municípios a partir da Constituição de 1988, relacionado ao seu reconhecimento como entes federativos e à descentralização política e tributária com ênfase nos municípios;

- a importância dos governadores no sistema político, o que, entretanto, não significa um poder igualmente expressivo da esfera estadual em todas as áreas da política pública;

- a existência de uma série de encargos compartilhados entre os governos no que se refere às políticas de corte social;

- a existência de mais de cinco mil municípios (o que amplia o número de orçamentos envolvidos), na sua maioria de pequeno ou médio porte, e com limitada capacidade financeira e administrativa para desenvolver todas as responsabilidades sobre as políticas públicas que lhes são atribuídas;

- as marcantes desigualdades econômicas e sociais entre regiões, estados e principalmente entre municípios.

\section{Desequilíbrios fiscais, ajuste macroeconômico e financiamento público da saúde no Brasil}

Muitas são as críticas formuladas pelos especialistas do federalismo fiscal sobre o sistema tributário consolidado na Constituição de 1988 e anos subseqüentes. A revisão de todas elas foge ao escopo desse trabalho. São enfatizadas somente aquelas consideradas fundamentais para compreensão das repercussões sobre o financiamento descentralizado do SUS no período analisado.

Em geral, duas ordens de problemas são recorrentes. A primeira delas refere-se aos conflitos gerados pelos desequilíbrios verticais decorrentes da descentralização fiscal, enquanto a segunda diz respeito à incapacidade dos dispositivos do sistema tributário vigente corrigirem, e até mesmo acentuarem, as imensas desigualdades horizontais que demarcam a federação brasileira.

\section{Desequilíbrios verticais}

A literatura sobre o federalismo indica a relevância do papel do governo central em países heterogêneos como o Brasil. A União é importante, entre outros, para a coordenação nacional do processo de descentralização (criando incentivos, corrigindo assimetrias e compensando as dificuldades institucionais), a indução do desenvolvimento econômico, a redução das desigualdades subjacentes, a redistribuição de recursos financeiros e a equalização da capacidade de financiamento e gasto das esferas subnacionais. 
Não há dúvidas de que os recursos financeiros disponíveis da União devam ser adequados para o bom desempenho dessas funções.

No Brasil, a rigidez orçamentária ${ }^{4}$ decorrente da descentralização de recursos no pós-88 foi bastante significativa, impondo limites à atuação federal. Estima-se que a diminuição das receitas da União foi da ordem de 1,2\% do Produto Interno Bruto (PIB) na virada para os anos 90.

Essa 'perda' de receitas ocorreu devido à descentralização das competências tributárias e, principalmente, ao aumento das transferências federais obrigatórias na Constituição de 19885. Grande parte dos dois principais impostos da União - o Imposto de Renda (IR) e o Imposto sobre Produtos Industrializados (IPI) - ficou comprometida com a partilha fiscal. Contabilizadas as transferências do Fundo de Participação dos Municípios (FPM), do Fundo de Participação dos Estados (FPE) e dos novos fundos criados - os Fundos Regionais 6 e o Fundo de Compensação pela Exportação de Produtos Industrializados (IPI-Exportação) -, permanecem no orçamento fiscal federal cerca de $53 \%$ e $43 \%$ da arrecadação líquida do IR e do IPI (Oliveira e Rezende, 2005).

Considera-se que os municípios foram os principais beneficiados pela ampliação de recursos (Serra e Afonso, 2001). A prerrogativa dos governos locais na descentralização tributária tem dupla determinação: das receitas totais cedidas pela União, a maior parte vai para os municípios e também é significativa a parcela de transferência financeira obrigatória definida para os estados?.

Apesar dos números não permitirem grandes questionamentos com relação ao balanço final da descentralização tributária, é preciso considerar que a União não se comportou como um ente passivo nesse processo. Pelo contrário, sua reação à perda de receitas e à rigidez de seu orçamento aconteceu de forma rápida e intensa, a ponto de alguns autores sugerirem que, desde 1993, não tenha havido grandes variações na divisão das receitas disponíveis entre as três esferas de governo (Serra e Afonso, 2001; Faveret, 2002).

As motivações que suscitaram a reação da União relacionam-se à importância adquirida pelo ajuste fiscal na estratégia adotada para o alcance da estabilidade macroeconômica. Nos anos seguintes à Constituição, evidencia-se que a descentralização tributária não era incoerente com a transferência de encargos sociais prevista no plano legal, mas, sobretudo, com o modelo de atuação do Estado.

A descentralização almejada como meio para ampliação dos direitos sociais colidiu diretamente com os objetivos de liberalização econômica e retração do papel do Estado, pois os investimentos e o aumento dos gastos públicos necessários à universalização da cobertura de serviços essenciais como os da saúde, nos estados e municípios, eram incompatíveis com 
o equilíbrio fiscal. Assim, foi necessário estabelecer formas rígidas de contingenciamento e controle para evitar uma ampliação ainda maior da transferência de recursos e das despesas em âmbito local8. Vários foram os mecanismos utilizados pela União para recompor suas receitas tributárias e controlar o déficit decorrente dos aumentos das despesas nas esferas subnacionais de governo, todas com impacto negativo no financiamento da política de saúde.

Em primeiro lugar, ressalta-se a ampliação e contingenciamento das receitas destinadas ao financiamento da Seguridade Social. A forma como foi moldado o regime fiscal duplo instaurado na Constituição de 1988 permitiu que o movimento de recuperação de receitas pela União ocorresse (Rezende e Afonso, 2001). Enquanto no capítulo do Sistema Tributário Nacional foram definidas as fontes de receitas específicas de cada ente e os tributos e montantes a serem partilhados, as normas que estabelecem os recursos destinados à Seguridade Social não especificam nem os montantes a serem distribuídos entre as áreas - previdência, saúde e assistência social -, nem a parcelas que deveriam ser destinadas ao financiamento descentralizado da política de saúde oriundas do Orçamento Federal9. Assim, as contribuições sociais, cuja competência é exclusiva da União, são vinculadas ao financiamento dos serviços de saúde sem garantias quanto ao fluxo de receitas para os orçamentos municipais e estaduais, o que favoreceu a concentração do poder político sobre as decisões relativas à arrecadação e ao destino final desses recursos.

Durante os anos 90, assiste-se a uma série de alterações na legislação tributária nacional, que privilegiam a cobrança das contribuições sociais por parte da União. Entre essas medidas, destaca-se o aumento das alíquotas da Contribuição para o Financiamento da Seguridade Social (Cofins), da Contribuição sobre o Lucro Líquido das Empresas (CSLL) e do Programa de Integração Social/Programa de Formação do Patrimônio do Servidor Público (PIS/Pasep), além da implantação de novos tributos, como é o caso da Contribuição Provisória sobre a Movimentação Financeira (CPMF) em 199710. Por outro lado, o baixo interesse pelos tributos partilhados - IR e IPI - fez com que as transferências constitucionais obrigatórias não acompanhassem a evolução da carga tributária do país, ajudando a conter a própria descentralização fiscal prevista na Constituição (Mora, 1998).

Em 2002, a arrecadação total de tributos no Brasil chegou a 35,5\% do PIB. As contribuições sociais para o financiamento da Seguridade Social representaram $35 \%$ deste montante $(12,4 \%$ do PIB), tornando-se responsáveis pelo maior volume de recursos arrecadados (cerca de $51 \%$ do total) e atuando como principal fonte de receita disponível para cobrir os gastos da União (Oliveira e Rezende, 2005). Esse montante equivale a quase o dobro do IR e dez vezes o IPI apurados neste mesmo ano. 
No entanto, a recomposição de receitas e o aumento da carga tributária nacional não estiveram atrelados a um plano de ordenamento e fortalecimento do processo de transferência de encargos para os entes subnacionais. As contribuições sociais cresceram, uma vez que foram reapropriadas da Seguridade, tornando-a uma variável de ajuste do processo de estabilização. Os instrumentos de desvinculação dos recursos destinados à área social permitiram à União remunerar os gastos com amortizações e serviços da dívida e desafogar as contas do Orçamento Fiscal com despesas previdenciárias do governo federal (Lessa et al., 1997; Ugá e Marques, 2005).

Mora (1998) resume os mecanismos utilizados pela União para o contingenciamento e desvio no uso dos recursos da Seguridade Social na década de 1990. Primeiro, no período inflacionário, através dos atrasos na liberação; posteriormente, com o Plano Real e a estabilização, criou-se o Fundo Social de Emergência (FSE), com receitas oriundas de impostos e de contribuições sociais (com exceção das transferências constitucionais e da contribuição sobre a folha de salários)

Proposto para durar dois anos (1994 e 1995), o FSE é recriado sob a forma de Fundo de Estabilização Fiscal (FEF) em 1996, permanecendo em vigor até 1999. Em 2000, o FEF é reformulado e passa a denominar-se Desvinculação de Receitas da União (DRU) até os dias atuais. Alegando necessitar sanear financeiramente a Fazenda Pública Federal e estabilizar a economia (justificativa para o FSE e FEF) e, em seguida, maior autonomia e flexibilidade para alocação dos recursos públicos sem prejuízo das ações da Seguridade Social (justificativa para o DRU), por meio desses fundos, desde 1994, o governo central retira 20\% dos recursos da Seguridade Social (Dain, 2007).

A situação de vulnerabilidade do Ministério da Saúde (MS) em face do modelo econômico adverso e das posições da Fazenda permanece até meados desta década. De tal forma que, desde 2000, a saúde representa sempre menos de $17 \%$ do Orçamento da Seguridade Social (OSS) e cerca de 5\% da despesa efetiva federal, enquanto as despesas com juros, encargos e amortizações da dívida interna e externa abocanham grande parcela dos recursos da área social (Ugá e Marques, 2005). Levantamentos efetuados pelo Conselho Nacional de Saúde (CNS) indicam que, se fossem cumpridas as disposições previstas para implantação do OSS e não ocorressem desvios em relação ao uso dos recursos, a totalidade das despesas da União com a previdência social, saúde e assistência social teria sido custeada sem nenhum déficit pelas receitas orçamentárias (Brasil, 2003)11.

Um segundo mecanismo importante de controle utilizado pela União foi o corte nos investimentos públicos realizados no período. $\mathrm{O}$ aumento da carga tributária, portanto, também não se traduziu em investimentos e crescimento econômico. Publicações recentes revelam que os investimentos foram 
extremamente baixos e até mesmo caíram na segunda metade da década de 1990, o comportamento do PIB foi errático, sendo a maior cifra a de 5,9\% em 1994, e a taxa de desemprego foi recorde em relação a períodos anteriores, além do aumento da informalidade (Oliveira e Rezende, 2005; Ugá e Marques, 2005).

Na saúde, também é possível observar a baixa participação das despesas de capital na execução orçamentária do MS e a inexistência de uma política mais ampla para reduzir a iniqüidade na oferta e cobertura das ações e serviços do SUS. Entre 1995 até o início dos anos 2000, projetos especiais financiados com recursos de agências internacionais como o Banco Mundial e o Banco Interamericano de Desenvolvimento voltaram-se para investimentos em infra-estrutura, equipamentos, desenvolvimento institucional e capacitação profissional, mas estes, em 2002, representaram somente 2,6\% dos gastos do MS (Faveret, 2002).

As 'frustrações' da descentralização tributária foram complementadas pela interferência federal nas decisões das esferas subnacionais e restrição da autonomia federativa. Essa interferência se deu, principalmente, pela imposição de condicionalidades para as transferências constitucionais e gestão de recursos fiscais nas esferas subnacionais e para as renegociações sobre as dívidas públicas, que resultou em um importante programa de privatização de empresas estatais.

No princípio dos anos 90, os governos subnacionais já se encontravam endividados por problemas herdados no passado. Inicialmente, o ajuste de suas contas fiscais era feito por meio do congelamento de salários, do adiamento da execução de despesas orçamentárias, da indexação das receitas à inflação e, no caso dos estados, da obtenção de empréstimos junto a suas instituições financeiras (prática vigente desde os anos 80). Com a estabilidade, essas estratégias tornaram-se ineficazes, porquanto a ampliação do pagamento de juros comprometeu ainda mais o frágil equilíbrio orçamentário dessas instâncias.

As altas taxas de juros se colocaram como ingrediente importante na estratégia para conter a inflação por travar a demanda e garantir o afluxo de capital externo para o país. No entanto, implicaram uma economia menos dinâmica e incidiram sobre a arrecadação tributária dos estados e municípios. Devido aos fatores apontados, Rezende e Afonso (2002) afirmam que a deterioração das contas públicas na segunda metade dos anos 90 foi principalmente conseqüência de fatores exógenos: juros elevados e baixo crescimento econômico.

A restrição da autonomia dos estados é maior do que aquela imposta aos municípios. As estratégias montadas pelo governo federal para conter despesas estaduais, buscando o equilíbrio fiscal, implicaram amplo programa de renegociação de suas dívidas que, numa primeira fase, se deu em 
condições bastante favoráveis para os governos. O impacto perverso desses acordos é que eles causaram forte pressão sobre as contas nacionais, acentuando os conflitos verticais. A partir de 1995, o refinanciamento envolveu reformas do setor público, incluindo privatização de empresas estaduais.

Com o agravamento da crise macroeconômica e na esteira do abandono pelo governo federal das políticas de investimento regionais, os estados passaram a utilizar seu poder de gestão sobre as alíquotas do Imposto sobre Circulação de Mercadorias e Serviços (ICMS) como instrumento de política econômica, em prejuízo da arrecadação, com o objetivo de atrair novos investimentos e promover o desenvolvimento industrial. O fenômeno, conhecido como 'guerra fiscal', quando praticado sem a aprovação do conjunto dos estados é considerado ilegal no Brasil. No entanto, a falta de mecanismos regulatórios satisfatórios e a atuação do próprio Conselho Nacional de Política Fazendária (Confaz), composto pelos secretários de fazenda dos estados, acabaram acentuando sua ocorrência (Prado e Cavalcanti, 2000).

Em 2000, a Lei de Responsabilidade Fiscal (LRF), aprovada no Congresso Nacional, estabelece condições duras a serem observadas na gestão das contas públicas das três esferas de governo e nos três Poderes para sustentar a disciplina fiscal (Brasil, 2000). A lei enfatiza a transparência como condição para aumentar o controle dos contribuintes sobre as ações governamentais e estabelece, entre outras, que os gastos com pessoal não devem ultrapassar $60 \%$ das receitas líquidas correntes.

Garson (2003), analisando as receitas e despesas orçamentárias dos estados e municípios brasileiros em 2001, indica possíveis resultados positivos da implantação da LRF para os governos subnacionais. Reforça, porém, que outros fatores são necessários para a boa gestão orçamentária, entre eles, a disseminação de uma cultura de planejamento entre os administradores. Além disso, alerta para o fato de que, dependendo da composição orçamentária das esferas subnacionais - maior ou menor dependência de recursos setoriais -, a demanda sobre os gastos com pessoal pode ser acentuada. Nesse caso, as limitações sobre os gastos sendo extremamente severas implicam disponibilidade menor de receitas para áreas altamente dependentes desses recursos, como é o caso do SUS.

Não se pode ignorar o possível efeito das medidas discutidas acima no financiamento das ações e serviços descentralizados do SUS. Se estados e, principalmente, os municípios foram beneficiados pela descentralização tributária, dificilmente poderiam dar conta dos compromissos de universalização e integralidade da atenção à saúde, sem a participação efetiva da União nesse processo. Além disso, mesmo a publicação da emenda constitucional n. ${ }^{\circ} 29$ de 2000 (EC 29), ao definir patamares mínimos de despesas em saúde nos orçamentos descentralizados, não resolve o problema das 
desigualdades na capacidade de financiamento por meio de recursos próprios das instâncias subnacionais.

Machado (2007) levanta a hipótese de que a diminuição da participação da União, que passa de $72 \%$ para $52 \%$ da despesa pública total em saúde no período de 1992 a 2002, representa uma estratégia de deslocamento da responsabilidade sobre o gasto social para as esferas subnacionais, que nem sempre têm condições de assumir tais encargos. Seus argumentos são coerentes com outros autores que tendem a relativizar os benefícios evocados pela descentralização (entre outros, Arretche, 1997; Levcovitz et al., 2001; Souza, 2002). Os resultados da descentralização, portanto, estão atrelados às condições mais gerais em que ela se realiza e aos objetivos a serem atingidos. No contexto de restrição fiscal, o modelo de descentralização implementado no sistema de saúde serviu mais ao propósito de retração da União e de contenção de despesas do que de sua expansão, como gostariam seus idealizadores.

\section{Desequilíbrios horizontais}

O segundo grupo de problemas a que se referem os especialistas sobre o tema tributário diz respeito aos desequilíbrios interestaduais e intermunicipais que resultam principalmente das regras que informam as transferências redistributivas no Brasil. Na classificação aqui empregada, consideram-se redistributivos todos os fluxos de receitas que não guardam relação com a proporcionalidade das bases tributárias respectivas nas esferas que se apropriam dos recursos. Por isso, são os únicos que têm possibilidade de reduzir as desigualdades nas receitas disponíveis observadas entre jurisdições com distintas capacidades econômicas.

Conforme estudo coordenado por Prado (2003), em 2000, cerca de $68 \%$ do volume total de transferências intergovernamentais verificados no sistema de partilha fiscal se encaixavam nessa categoria. Entre elas, temos aquelas consideradas fluxos redistributivos clássicos, que não são exclusivos de determinados setores e, na sua maior parte, pode ser utilizado livremente pelas esferas subnacionais. Nesse grupo, os mais importantes são o FPE e FPM ( $41 \%$ do total dos fluxos redistributivos) transferidos pela União, respectivamente, para estados e municípios; e o sistema cota-parte estadual ( $9,4 \%$ do total das transferências redistributivas), transferido para os municípios, que inclui $6,25 \%$ do ICMS arrecadado.

Além dessas transferências, agregam-se as transferências redistributivas setoriais, ou seja, aquelas que se restringem a funções específicas e não atuam diretamente sobre a capacidade geral de gasto do governo que recebe os recursos. Este subsistema de partilha interfere apenas na alocação de tri- 
butos destinados a duas áreas de atuação do setor público - a educação (as transferências multigovernamentais do Fundo Nacional de Desenvolvimento do Ensino Fundamental e Valorização do Magistério - Fundef ${ }^{12}$ ) e a saúde (as transferências federais do SUS13). Enquanto o Fundef representava cerca de $30 \%$ dos recursos redistributivos totais transferidos em 2000, o SUS era cerca de 20\% (Prado, 2003).

Uma primeira análise importante sobre o sistema de partilha brasileiro é que ele reforça a função da União em detrimento dos estados na realocação dos recursos que tenham potencial para equalização fiscal. Essa situação acarreta grande dependência dos municípios em relação ao governo federal. Levantamento efetuado a partir do Sistema de Informações de Orçamentos Públicos em Saúde em 2002 indica que, considerada a receita total dos municípios, $80 \%$ dos recursos são derivados de transferências e, dessas, cerca de $50 \%$ se originam da União (Gráfico 1). Em contraposição, leva também à grande fragilidade das conexões administrativas e orçamentárias existentes entre as jurisdições locais e os estados. O padrão que predomina privilegia as articulações entre o governo central e cada um dos governos municipais, o que dificulta a integração de políticas e a formação de redes de serviços.

\section{Gráfico 1}

Composição percentual das receitas correntes municipais - Brasil, 2002

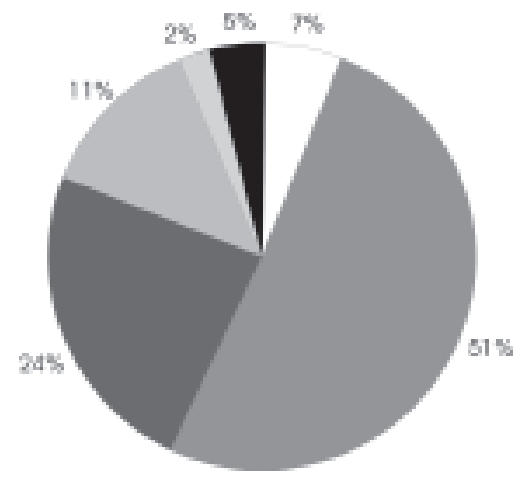

$\square$ Arrecadação tributária própria

- Transferências da União

- Transferências dos estados

- Transferências multigovernamentais (Fundef)

- Transferências de convênios

- Outras receitas correntes

Fonte: Siops/Datasus/MS (receitas orçamentárias) e IBGE (população estimada). Elaboração própria.

Entretanto, a pergunta fundamental a ser feita é se o sistema de transferência de recursos redistributivos, tal como está estruturado, possibilita a diminuição das desigualdades das receitas disponíveis das esferas subnacionais.

O estudo coordenado por Prado (2003) indica que o FPE tende a ser mais redistributivo que o FPM no plano inter-regional, proporcionando ganhos substantivos de receita aos estados situados nas regiões Norte, 
Nordeste e Centro-Oeste em detrimento das regiões Sudeste e Sul do país. As dificuldades redistributivas do FPM concentram-se nos municípios não capitais, pois cerca de um terço desses recursos é reservado ao Sudeste e ele acaba privilegiando estados mais desenvolvidos, que possuem grande número de pequenos municípios, como São Paulo, Rio Grande do Sul e Minas Gerais.

Mas a redistribuição do FPE não é suficiente para homogeneizar as receitas orçamentárias entre os estados da federação e seus agregados regionais. Observam-se importantes disparidades na receita final per capita (resultado da arrecadação e do sistema de partilha como um todo) dos estados brasileiros.

No plano dos municípios, as disparidades encontradas na receita disponível per capita entre as capitais e municípios de porte populacional diferenciado são gritantes. De tal monta que: a) o sistema privilegia claramente as capitais ( $23 \%$ da população) e os municípios abaixo de 5 mil habitantes $(2,7 \%$ da população) em relação aos municípios na faixa de 10 mil a 100 mil habitantes (41\% da população brasileira); b) a receita per capita das capitais é 80 \% mais alta que a enorme parcela da população que reside em municípios intermediários; c) os municípios com população abaixo de 5 mil habitantes têm uma receita per capita superior às capitais; e d) o crescimento da receita nos municípios com mais de 75 mil habitantes não está associado à arrecadação ou ao FPM, mas, fundamentalmente, à devolução tributária e aos demais fluxos redistributivos.

De fato, a falta de planejamento integrado das regras que orientam as transferências nos diversos subsistemas de partilha no Brasil, assim como a fixação dos coeficientes de distribuição dos Fundos de Participação ocorrida em 1989 dificultam a correção de assimetrias. Destaca-se que, desde 1992, os coeficientes não são revistos com tanta regularidade, o que acaba tornando difícil a dinâmica da correção dos desequilíbrios horizontais na federação (Prado et al., 2003).

As limitações dos fluxos redistributivos clássicos trazem à tona a importância das transferências setoriais e, particularmente, das transferências regulares do SUS aportadas pela União. No entanto, essas transferências são orientadas para a provisão de ações e serviços de saúde e possuem uma lógica interna que não se coaduna com o restante do sistema de partilha. Até o momento, os recursos são transferidos sem qualquer aferição das diferenças nas capacidades econômicas e dos efeitos das transferências constitucionais para as esferas subnacionais, o que resulta na maior ou menor disponibilidade de recursos próprios destinados à saúde, segundo os preceitos da EC 29.

Pesquisas demonstram que o efeito redistributivo dos recursos transferidos regularmente para a saúde é limitado tanto para os governos esta- 
duais como para os municipais (Prado, 2003; Prado et al., 2003). Eles beneficiam as regiões Sudeste e Sul e não se diferenciam significativamente nos municípios de porte intermediário e as capitais. Outros levantamentos, entretanto, indicam resultados mais satisfatórios da redistribuição fiscal alcançada mediante os fluxos próprios do SUS para os municípios, pois o sentido da redistribuição é oposto ao de outros recursos, o que acaba gerando determinadas compensações e diminuindo o grau de desigualdade entre as receitas disponíveis (Dain e Faveret, 1999; Dain, 2000; Garson, 2004; Gershman e Viana, 2005; Araujo e Oliveira, 2001).

Pesquisa conduzida com base nos dados do Siops em 2002 evidencia que os efeitos dos recursos federais do SUS sobre os orçamentos das esferas subnacionais não podem ser desprezados. Sobre o mesmo percentual de vinculação de recursos próprios estipulado pela EC 29, diferentes disponibilidades de receitas destinadas à saúde são geradas, sendo significativo o papel do MS na redistribuição de recursos financeiros para regiões e estados menos desenvolvidos. A Tabela 1 ilustra um importante efeito de redistribuição de recursos das transferências federais do SUS para municípios situados nas regiões Norte, Nordeste e Centro-Oeste do país se comparado a outros mecanismos previstos no sistema de partilha fiscal. Essa redistribuição foi possível principalmente por meio dos recursos vinculados ao Piso de Atenção Básica Variável, que incluem aqueles voltados para o Programa de Agentes Comunitários de Saúde e o Saúde da Família (Pacs/PSF).

Tabela 1

Receitas municipais per capita relativas. Razão entre os valores medianos observados nos municípios agrupados por região e UF e a mediana nacional - Brasil, 2002

\begin{tabular}{lccccc}
\hline Região & Arrecadação tributária própria* & ICMS & FPM & SUS & Fundef \\
\hline Centro-Oeste & 154,6 & 152,3 & 111,1 & 115,6 & 86,8 \\
Nordeste & 43,3 & 40,0 & 95,7 & 106,1 & 127,4 \\
Norte & 56,7 & 65,1 & 75,2 & 103,0 & 118,7 \\
Sudeste & 155,9 & 133,2 & 101,0 & 90,3 & 81,1 \\
Sul & 154,6 & 156,9 & 120,7 & 91,1 & 90,0 \\
Total & 100,0 & 100,0 & 100,0 & 100,0 & 100,0 \\
\hline
\end{tabular}

Fonte: Siops/Datasus/MS (receitas orçamentárias) e IBGE (população estimada). Elaboração própria.

Nota: $\left(^{*}\right)$ Inclui a arrecadação direta de impostos, taxas e contribuições de melhoria, a dívida ativa, multas e juros de mora de tibutos.

Contudo, as transferências federais do SUS não tiveram, até o início dos anos 2000, volume suficiente para romper com as desigualdades inter e intra-regionais das receitas públicas municipais, nem com a situação desfavorável dos municípios médios. Ambas situações são decorrentes das diferenças na arrecadação direta de impostos e de apropriação de outras transferências não exclusivas da saúde oriundas da União e estados 
(respectivamente, do FPM e ICMS), que compõem a base vinculável da EC 29 (Gráfico 1 e Gráfico 2).

Gráfico 2

Receitas correntes vinculadas à saúde nos municípios agrupados por região -

valores medianos em real (R\$) per capita - Brasil, 2002

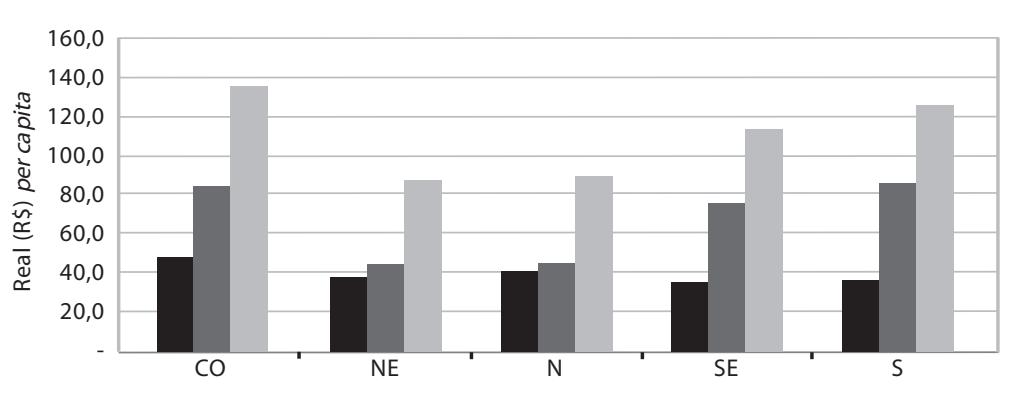

- Receitas correntes com destino vinculado à saúde no ingresso orçamentário

- Receitas correntes vinculadas à saúde pela EC 29

- Receitas correntes totais vinculadas à saúde

Fonte: Siops/Datasus/MS (receitas orçamentárias) e IBGE (população estimada). Elaboração própria.

Nota: As receitas correntes com destino vinculado à saúde no ingresso orçamentário são compostas principalmente pelas transferências federais do SUS. As receitas correntes vinculadas à saúde pela EC 29 incluem as diretamente arrecadadas e as transferências constitucionais, definidas como base para aplicação dos $15 \%$ de vinculação.

\section{Gráfico 3}

Receitas correntes vinculadas à saúde nos municípios agrupados por porte populacional e capitais valores medianos em real (R\$) per capita - Brasil, 2002

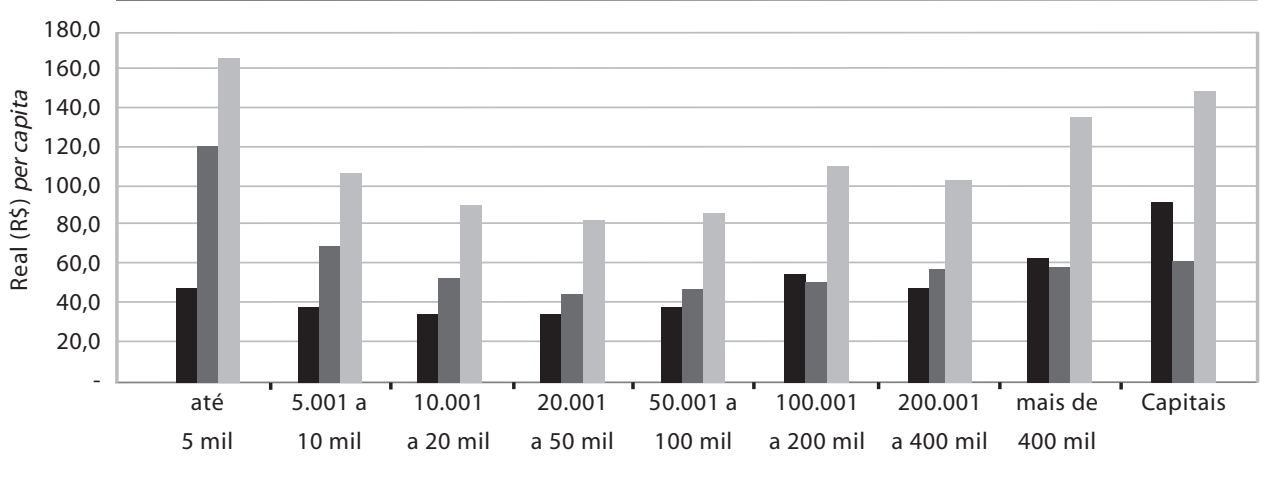

- Receitas correntes com destino vinculado à saúde no ingresso orçamentário

- Receitas correntes vinculadas à saúde pela EC 29

- Receitas correntes totais vinculadas à saúde

Fonte: Siops/Datasus/MS (receitas orçamentárias) e IBGE (população estimada). Elaboração própria.

Nota: As receitas correntes com destino vinculado à saúde no ingresso orçamentário são compostas principalmente pelas transferências federais do SUS. As receitas correntes vinculadas à saúde pela EC 29 incluem as diretamente arrecadadas e as transferências constitucionais, definidas como base para aplicação dos 15 \% de vinculação. 
Como resultado, os municípios do Norte, Nordeste e os com população de 20 mil a 100 mil habitantes, se comparados a outros grupos: a) possuem menores chances de ampliação de recursos próprios para a saúde como efeito da vinculação estabelecida pela EC 29, já que a disponibilidade dessas fontes é relativamente mais baixa; b) precisam empreender maior esforço fiscal e comprometer uma parcela mais elevada de seus orçamentos para garantirem a adequação dos recursos às suas necessidades de gasto em saúde; e c) são os que mais dependem das transferências federais da saúde para ampliar suas receitas destinadas ao SUS e, por isso, estão mais sujeitos aos mecanismos de indução e controle do MS.

No âmbito estadual, percebem-se importantes diferenças entre as regiões devido à capacidade de arrecadação do ICMS e apropriação do FPE, sendo particularmente crítica a situação dos estados do Nordeste (ver Tabela 2 na página seguinte). Em grande parte, os repasses federais regulares do SUS para os estados estão atrelados ao modelo de descentralização e repartição de funções adotado. Assim, os recursos federais voltados para a saúde nos estados não têm um sentido nítido, submetendo-se aos processos de ajustes regionais da política. Ao mesmo tempo em que privilegiam os estados do Sul também acabam sendo relevantes para alguns estados do Norte e Nordeste, para o Distrito Federal e Goiás, no Centro-Oeste, e para Minas Gerais, no Sudeste.

Considerando as regras vigentes, comprova-se que o grau de vinculação orçamentária à saúde das esferas subnacionais no Brasil é semelhante ao observado em outros países (cerca de $17 \%$ para os municípios e $12 \%$ para os estados). No entanto, a vinculação brasileira mantém a heterogeneidade nas condições de financiamento descentralizado do SUS, sendo acompanhada pela fragmentação e multiplicidade de dispositivos utilizados para transferência de recursos federais e forte determinação no uso dos recursos. Essa é a contraface perversa do incremento das transferências regulares da saúde, mantidas as condições do federalismo fiscal: sem a garantia de patamares semelhantes de recursos públicos nas esferas municipais e estaduais, há perda da autonomia alocativa e segmentação da gestão orçamentária dos tributos destinados à saúde.

Em síntese, as desigualdades nas receitas disponíveis entre estados e municípios permanecem extremamente elevadas no início dos anos 2000. Se as transferências redistributivas do sistema tributário brasileiro permitem que recursos do núcleo mais desenvolvido do país cheguem a regiões mais atrasadas economicamente, isso é feito de forma quase aleatória, pois não é fruto de um planejamento prévio. Como sugerido por Prado (2003), o impacto não poderia ser outro: as transferências, em seu conjunto, criam e reproduzem desigualdades tão grandes ou maiores do que aquelas observadas na arrecadação tributária inicial. 
Tabela 2

Receitas correntes vinculadas à saúde nos estados agrupados por região - em real (R\$) per capita Brasil, 2002

\begin{tabular}{|c|c|c|c|c|}
\hline Região & UF & $\begin{array}{l}\text { Receitas correntes com destino } \\
\text { vinculado à saúde no ingresso } \\
\text { orçamentário }\end{array}$ & $\begin{array}{c}\text { Receitas correntes } \\
\text { vinculadas à saúde } \\
\text { pela EC } 29\end{array}$ & $\begin{array}{l}\text { Receitas correntes totais } \\
\text { vinculadas à saúde }\end{array}$ \\
\hline \multirow[t]{5}{*}{$\mathrm{CO}$} & DF & 319,5 & 192,5 & 512,0 \\
\hline & $\mathrm{GO}$ & 37,1 & 72,3 & 109,4 \\
\hline & MT & 19,6 & 95,0 & 114,6 \\
\hline & MS & 19,4 & 80,7 & 100,1 \\
\hline & Total & 98,9 & 110,1 & 209,0 \\
\hline \multirow[t]{10}{*}{ NE } & $A L$ & 27,7 & 60,8 & 88,5 \\
\hline & BA & 12,9 & 55,8 & 68,8 \\
\hline & CE & 29,6 & 56,4 & 86,0 \\
\hline & MA & 11,0 & 48,9 & 59,9 \\
\hline & PB & 37,2 & 61,1 & 98,3 \\
\hline & PE & 23,9 & 58,1 & 82,0 \\
\hline & $\mathrm{PI}$ & 21,4 & 55,2 & 76,7 \\
\hline & $\mathrm{RN}$ & 12,5 & 73,7 & 86,2 \\
\hline & SE & 17,1 & 93,5 & 110,6 \\
\hline & Total & 21,5 & 62,6 & 84,1 \\
\hline \multirow[t]{8}{*}{$\mathrm{N}$} & $A C$ & 47,9 & 181,0 & 228,8 \\
\hline & AP & 33,0 & 196,9 & 229,8 \\
\hline & AM & 35,9 & 90,7 & 126,6 \\
\hline & PA & 27,9 & 54,1 & 82,0 \\
\hline & RO & 11,8 & 93,4 & 105,1 \\
\hline & $\mathrm{RR}$ & 29,6 & 216,9 & 246,6 \\
\hline & TO & 5,4 & 124,7 & 130,2 \\
\hline & Total & 27,3 & 136,8 & 164,2 \\
\hline \multirow[t]{5}{*}{ SE } & ES & 15,3 & 93,7 & 108,9 \\
\hline & MG & 29,0 & 63,3 & 92,3 \\
\hline & RJ & 24,5 & 79,0 & 103,5 \\
\hline & $\mathrm{SP}$ & 16,4 & 103,1 & 119,5 \\
\hline & Total & 21,3 & 84,8 & 106,1 \\
\hline \multirow[t]{4}{*}{$S$} & PR & 38,4 & 71,7 & 110,2 \\
\hline & RS & - & 77,4 & 77,4 \\
\hline & SC & 48,4 & 80,0 & 128,4 \\
\hline & Total & 28,9 & 76,4 & 105,3 \\
\hline Total & & 35,3 & 93,7 & 129,0 \\
\hline
\end{tabular}

Fonte: Siops/Datasus/MS (receitas orçamentárias) e IBGE (população estimada). Elaboração própria.

Nota: As receitas correntes com destino vinculado à saúde no ingresso orçamentário são compostas principalmente pelas transferências federais do SUS. As receitas correntes vinculadas à saúde pela EC 29 incluem as diretamente arrecadadas e as transferências constitucionais federais, definidas como base para aplicação dos $12 \%$ de vinculação. 


\section{Conclusões}

A revisão da literatura efetuada nesse artigo indica a plasticidade da engenharia fiscal no Brasil, que, simultaneamente, promove a descentralização e permite a recentralização de receitas, atende a múltiplas funções e adota formatos diversos de partilha de recursos financeiros entre os governos. No entanto, se do ponto de vista teórico esse padrão possibilita a amenização de tensões federativas, os resultados finais desse modelo flexível e diversificado para o financiamento do SUS são insatisfatórios. Não há garantias para a oferta de um conjunto de serviços e benefícios comuns aos cidadãos nas diferentes regiões do país, e a autonomia decisória dos entes subnacionais, sendo restrita, impossibilita a adequação regional no destino dos recursos tributários.

Vários fatores explicam os problemas evidenciados que permanecem como desafios a serem enfrentados no âmbito da reforma do sistema tributário brasileiro:

- desequilíbrios verticais e limites impostos à atuação do governo central, decorrentes da descentralização tributária e da ausência de um plano nacional que garanta as condições adequadas à transferência de encargos sociais por meio de participação da União nesse processo.

- defasagem do modelo de partilha fiscal adotado, já que suas bases (os fundos de participação) remontam a uma conjuntura política e econômica bastante diversa (segunda metade da década de 1960);

- inadequação dos critérios de redistribuição de recursos, incapazes de atender aos requisitos da diminuição das desigualdades nas receitas disponíveis entre os governos subnacionais frente às mudanças econômicas e demográficas verificadas no país desde o final dos anos 70;

- ausência de planejamento dos diversos subsistemas de transferência, incluindo as transferências federais do SUS, o que dificulta a correção das desigualdades na receita disponível entre os estados e municípios situados em distintas regiões do país;

- insuficiência de mecanismos redistributivos que levem em conta as necessidades de recursos fiscais, uma vez que a capacidade econômica e de renda local, o esforço fiscal das esferas subnacionais e as diferenças nas demandas e custos dos serviços interferem na capacidade de financiamento descentralizado de políticas setoriais e na oferta de serviços;

- fragilidade das conexões orçamentárias entre as esferas estaduais e municipais e entre instâncias do mesmo nível de governo, o que não favorece a integração de políticas específicas no âmbito regional e estadual.

Mas se os fatores de ordem institucional são relevantes, o contexto político e econômico da década de 1990 expandida exacerbou os efeitos distorcidos do sistema tributário sobre a receita disponível e a capacidade de 
gasto das instâncias governamentais. Nesse sentido, o federalismo fiscal pragmático brasileiro, aderindo à terminologia proposta por Fiori (1995), não obedeceu à expansão do papel do Estado na proteção social e não promoveu a superação das desigualdades regionais, tendo seguido, principalmente, os ditames da política macroeconômica de estabilização e os ajustes estruturais da economia impostos por agentes externos, organismos multilaterais e interesses privados.

Como a descentralização tributária e a ampliação dos direitos e da responsabilidade do Estado foram inscritas na Constituição de 1988, anteriormente à estabilização, assiste-se ao longo da década à implementação de vários dispositivos pela área fazendária da União que possibilitaram a recuperação de sua receita disponível, o financiamento das altas taxas de juros, a contenção dos gastos públicos nas esferas subnacionais e o superávit fiscal. Portanto, a "ditadura" da política econômica na década de 1990 não permitiu que a descentralização de recursos e encargos sociais se realizasse plenamente no Brasil, pois ela comprometia as variáveis de controle da inflação e atração de capital externo.

Lamentavelmente, nesses longos anos, predomina a visão da saúde como fonte de despesa, afastando-a da idéia de direito social ou valor humano. Desvios no uso de recursos da Seguridade Social, oscilações de fontes e instabilidade no aporte de receitas do MS marcaram o financiamento do SUS e limitaram os investimentos e transferências correntes federais realizadas para os estados e municípios.

Outro aspecto importante do federalismo fiscal nos anos 90 é que ele demonstra a força da União e dos interesses políticos, econômicos e locoregionais por ela representados, a fragilidade das esferas subnacionais e suas máquinas administrativas, dos valores federativos e da própria federação brasileira.

Almeida (2005, p. 38) afirma que "a idéia de que é no centro do sistema político que se pode discernir com mais nitidez as soluções mais adequadas dos problemas da agenda pública é uma representação arraigada das elites políticas, burocráticas e profissionais do país". Existe, portanto, uma cultura centralizadora dos dirigentes nas três esferas de governo, e os impulsos descentralizadores também induzem a movimentos contrários. Isso ajuda a explicar a convergência de ambos os aspectos - centralização e descentralização - na dimensão fiscal e na própria política de saúde.

Por outro lado, no Brasil, diferentemente de outros países, a Constituição e as leis federais não se traduzem como garantias para o pacto federativo, o que contribui para um clima de incertezas e tensões permanentes. Os canais de negociação intergovernamental também são insuficientes para a criação de mecanismos de coordenação e cooperação que expressem objetivos comuns e diminuam a competição entre os entes federados por recur- 
sos financeiros. Ainda aqui, o grau de tolerância às desigualdades regionais acaba comprometendo os princípios federativos de interdependência e autonomia, pois não há precisão da eqüidade ou dos padrões nacionais que se quer alcançar nem das capacidades institucionais que se quer promover por meio do sistema tributário, no qual a saúde se insere.

\section{Notas}

1 Professora da Escola Nacional de Saúde Pública Sergio Arouca da Fundação Oswaldo Cruz (Ensp/Fiocruz). Doutora em Saúde Coletiva pela Universidade do Estado do Rio de Janeiro (Uerj).<luciana@ensp.fiocruz.br>

$2 \mathrm{O}$ conceito de receita disponível inclui a arrecadação própria de tributos (impostos, taxas e contribuições), mais ou menos as transferências intergovernamentais previstas nos sistemas de partilha fiscal. Refere-se, portanto, ao resultado final da receita após as transferências intergovernamentais.

3 Para países como Alemanha, Canadá, Austrália e, em menor proporção, Suíça, as denominadas solidary transfers são fundamentais para garantir uma diminuição das diferenças orçamentárias entre as esferas subnacionais de governo, embora nem sempre considerem as necessidades efetivas de gasto. Os EUA, se comparados aos países europeus e ao Canadá, apresentam desigualdades interestaduais mais expressivas, mas não adotam nenhum esquema regular de equalização fiscal. Os graus de tolerância às desigualdades observadas nas diversas federações refletem, em última análise, o quanto nessas organizações federativas os governos subnacionais abrem mão de sua autonomia em função da eqüidade nacional e da garantia de determinados padrões nacionais de políticas públicas.

4 A rigidez orçamentária da União é freqüentemente associada à sua baixa capacidade para realizar escolhas orçamentárias e realocar recursos (Rezende e Cunha, 2003).

5 Segundo Varsano (1996), outros fatores também contribuíram para a diminuição da receita disponível da União nos anos 90, tais como a impossibilidade política de se recuperarem as condições das finanças públicas e da carga tributária por meio de reformas mais amplas, a estagnação econômica e aceleração da inflação, e as condições precárias da administração fazendária federal.

6 Os fundos regionais para as regiões Centro-Oeste, Norte e Nordeste agregam, respectivamente, $1,8 \%, 0,6 \%$ e $0,6 \%$ (total equivalente a 3\%) do IR e do IPI (Brasil, 1998), que devem ser aplicados em programas de financiamento voltados para o setor produtivo através das instituições financeiras de caráter regional.

7 Prado (2003) estima que cerca de 30\% das receitas estaduais são transferidas aos municípios, incluindo os $25 \%$ do Imposto sobre Circulação de Mercadorias e Serviços (ICMS) arrecadado e $25 \%$ do IPI-Exportação recebido da União. 
8 Entre 1988 e 1990, verifica-se que os governos estaduais aumentaram cerca de $2 \%$ do PIB de sua receita disponível, despendendo cerca de $74 \%$ desse ganho com pagamento de pessoal. Nos municípios, $30 \%$ da receita adicional foram gastos com aumentos de salários (Varsano, 1996). As principais fontes de despesa foram justamente as áreas de saúde e educação, para quais as responsabilidades dessas instâncias ampliaram-se e ocorreram transferências importantes de equipamentos e serviços. Essa situação se consolida na década frente à contenção de despesas pelos órgãos federais. Em 1999, Serra e Afonso (2001) indicam que os governos subnacionais respondem por $68 \%$ da folha de pagamento de servidores públicos em atividade, $68 \%$ de outros custeios e $80 \%$ dos investimentos fixos.

${ }^{9} \mathrm{~A}$ indefinição quanto ao aporte de receitas dos orçamentos municipais e estaduais para saúde no capítulo da Seguridade Social também induziu a uma participação não uniforme das esferas subnacionais no financiamento setorial, já que nem todas têm as mesmas prerrogativas financeiras e priorizam a saúde como área de gasto e investimento. Essa situação é parcialmente contornada após a promulgação da emenda constitucional n. ${ }^{\circ} 29$, de 2000, que estabelece patamares mínimos de despesas em ações e serviços públicos de saúde para municípios, estados e União (Brasil, 2000).

10 Na segunda metade da década, num contexto de crise do financiamento da saúde, é negociada pelo Ministério da Saúde a criação de uma fonte específica de financiamento para o setor. No entanto, a CPMF, aprovada ao final de 1996 e implantada em 1997, não gerou o aumento de recursos esperado devido à substituição relativa de fontes e sua utilização para cobrir outras finalidades de despesas (Piola e Biazoto Jr., 2001).

11 Infelizmente, essa situação mantém-se na atualidade. Em recente publicação, a Associação Nacional dos Auditores Fiscais da Previdência Social indica que, em 2005, a DRU carreou do OSS para o Orçamento Fiscal cerca de R\$32 bilhões (Anfip, 2006). O superávit do OSS, segundo as estimativas divulgadas, chega a R\$ 56 bilhões.

$12 \mathrm{O}$ Fundef é classificado como multigovernamental, pois tem origem nas receitas próprias dos municípios, estados e da União. Em 2007 é substituído pelo Fundo de Manutenção e Desenvolvimento da Educação Básica e de Valorização dos Profissionais de Educação (Fundeb).

13 As transferências federais do SUS referem-se aos recursos transferidos do Fundo Nacional de Saúde para os Fundos Municipais e Estaduais de Saúde, que englobam o Piso de Atenção Básica fixo (PAB fixo), o Piso de Atenção Básica Variável (PAB variável), os recursos da média e alta complexidade ambulatorial e hospitalar, e aqueles vinculados a programas especiais do Ministério da Saúde e ao Fundo de Ações Estratégicas e Compensação (Faec). 


\section{Referências}

AFFONSO, Rui de Britto Álvares; SILVA, Pedro Luiz Barros. Notas dos organizadores. In: (Orgs.). Reforma tributária e federação. São Paulo: Fundap, 1995. p. 6-9.

ALMEIDA, Maria Hermínia Tavares. Recentralizando a federação? Revista de Sociologia e Política, Curitiba, n. 24, p. 29-40, 2005.

ARAUJO, Érika; OLIVEIRA, Paulo André. Federalismo fiscal; Receita municipal: a importância das transferências do FPM e do SUS. Informe-se, Rio de Janeiro: BNDES, n.28, 2001.

ARRETCHE, Marta T. S. O mito da descentralização como indutor de maior democratização e eficiência das políticas públicas. In: GERSCHMAN, S.; VIANNA, M. L. W. (Orgs.). A miragem da pós-modernidade: democracia e políticas sociais no contexto da globalização. Rio de Janeiro: Editora Fiocruz, 1997. p. 127-152.

ASSOCIAÇÃO NACIONAL DOS AUDITORES FISCAIS DA PREVIDÊNCIA SOCIAL. Análise da Seguridade Social em 2005. Brasília: Fundação Anfip de Estudos da Seguridade Social, 2006. 56 p.

BANTING, Keith; CORBETT, Stan. Federalismo y políticas de atención a la salud. In: AUCLAIR, C.; CARRASCO, C. H. G. (Ed.). Federalismo y políticas de salud: descentralización y relaciones intergubernamentales desde una perspectiva comparada. Ottawa: Foro de Federaciones/Ciudad de México: Instituto Nacional para el Federalismo y Desarrollo Municipal, 2002. p. 5-41.

BRASIL. Constituição (1988). Emenda constitucional n. ${ }^{\circ} 29$, de 13 de setembro de 2000. Altera os artigos 34, 35, 156, 160, 167 e 198 da Constituição Federal e acrescenta artigo ao Ato das Disposições Constitucionais Transitórias, para assegurar os recursos mínimos para o financiamento das ações e serviços públicos de saúde. Diário Oficial [da República Federativa do Brasil], Brasília, DF, 14 set. 2000.

BRASIL. Lei complementar $n .{ }^{\circ} 101$, de 4 de maio de 2000. Estabelece normas de finanças públicas voltadas para a responsabilidade na gestão fiscal e dá outras providências. Diário Oficial [da República Federativa do Brasil], Brasília, DF, 05 de maio 2000, p. 1.

BRASIL. Ministério da Fazenda. Secretaria do Tesouro Nacional. O que você precisa saber sobre o FPM e FPE. Brasília, nov. 1998. $39 \mathrm{p}$.

BRASIL. Ministério da Saúde. Conselho Nacional de Saúde. Reunião da Comissão de Orçamento e Financiamento do Conselho Nacional de Saúde-Cofin/CNS. Relatório. Reunião de 4 e 5 fev. 2003, 2003.

DAIN, Sulamis. Dilemas do Estado diante da nova ordem econômica e social. In: VALLADARES, Licia; COELHO, Magda Prates (Orgs.). Governabilidade e pobreza no Brasil. Rio de Janeiro: Civilização Brasileira, 1995. p. 65-104.

Do direito social à mercadoria. Tese (Concurso Público de Títulos e Provas para Professor Titular) - Instituto de Medicina Social, Universidade do Estado do Rio de Janeiro, Rio de Janeiro, 2000.

. Os vários mundos do financiamento da saúde no Brasil: uma tentativa de integração. Ciência \& Saúde Coletiva, v.12, supl., nov., 2007, p. 1851-1864.

DAIN, Sulamis; FAVERET, Ana Cecília de Sá Campelo. Entre o neofederalismo e o ornitorrinco. Inteligência, Rio de Janeiro, n. 6, p. 43-52, 1999.

FAVERET, Ana Cecília de Sá Campelo. Federalismo fiscal e descentralização no Brasil: o financiamento da política de saúde na década de 90 e início dos anos 2000. 2002. Tese (Doutorado em Saúde Coletiva) - Instituto 
de Medicina Social, Universidade do Estado do Rio de Janeiro, Rio de Janeiro, 2002.

FIORI, José Luiz. O federalismo frente ao desafio da globalização. Rio de Janeiro: Instituto de Medicina Social, Universidade do Estado do Rio de Janeiro, 1995 (Série Estudos em Saúde Coletiva, n. 15).

GARSON, Sol. Análise do desempenho fiscal dos municípios das áreas metropolitanas: relatório da atividade $3 \mathrm{c}$ do Projeto Análise das Regiões Metropolitanas do Brasil. Rio de Janeiro: Observatório das Metrópoles/ Federação de Órgãos para a Assistência Social e Educacional/Instituto de Pesquisa e Planejamento Urbano e Regional, 2004.

Planejamento público e responsabilidade fiscal: um edifício em construção. In: SEMINÁRIO REGIONAL DE POLÍTICA FISCAL, 15., 2003, Santiago de Chile. Santiago de Chile: Cepal, Organização das Nações Unidas, 2003. Mimeografado, 19 p.

GERSHMAN, Silvia; VIANA, Ana Luiza D'Ávila. Descentralização e desigualdades regionais em tempos de hegemonia liberal. In: LIMA, Nísia Trindade et al. (Orgs.). Saúde e democracia: história e perspectivas do SUS. Rio de Janeiro: Fiocruz, 2005. p. 307-351.

LESSA, Carlos et al. Pobreza e política social: uma leitura da questão da exclusão nos anos 90. Praga - Estudos Marxistas, São Paulo, n. 3, p. 63-87, 1997.

LEVCOVITZ, Eduardo; LIMA, Luciana Dias; MACHADO, Cristiani Vieira. Política de saúde nos anos 90: relações intergovernamentais e o papel das normas operacionais básicas. Ciência \& Saúde Coletiva, Rio de Janeiro, v. 6, n. 2, p. 269-291, 2001.

LIMA, Luciana Dias. Federalismo, relações fiscais e financiamento do Sistema Único de Saúde: a distribuição de receitas vinculadas à saúde nos orçamentos municipais e estaduais. Rio de Janeiro: Museu da República, 2007. 352 p.
MACHADO, Cristiani Vieira ; LIMA, Luciana Dias; BAPTISTA, Tatiana Wargas de Faria . Configuração Institucional e o Papel dos Gestores no Sistema Único de Saúde. In: MATTA, Gustavo Correa; PONTES, Ana Lúcia de Moura Pontes (Orgs.). Politicas de saúde: a organização e a operacionalização do Sistema Único de Saúde. 1. ed. Rio de Janeiro: EPSJV/Fiocruz, 2007. p. 139-162.

MACHADO, Cristiani Vieira. Direito universal, politica nacional: o papel do Ministério da Saúde na política de saúde brasileira de 1990 a 2002. Rio de Janeiro: Museu da República, 2007. 504 p.

MORA, Mônica. O processo de endividamento dos estados: problemas e limites à descentralização e à autonomia. 1998. Dissertação (Mestrado em Economia) - Instituto de Economia, Universidade Federal do Rio de Janeiro, Rio de Janeiro, 1998.

OLIVEIRA, Fabrício Augusto; REZENDE, Fernando. O Estado e a federação. In: REZENDE, F.; TAFNER, P. (Ed.). Brasil: o estado de uma nação. Rio de Janeiro: Ipea, 2005. p. 253-283

PIOLA, Sérgio Francisco; BIASOTO, Geraldo Júnior. Financiamento do SUS nos anos 90. In: NEGRI, Barjas; DI GIOVANNI, Geraldo (Orgs.). Brasil: radiografia da saúde. Campinas: Unicamp, 2001. p.219-232.

PRADO, Sérgio (Coord.); QUADROS, Waldemir; CAVALCANTI, Carlos Eduardo. Partilha de recursos na federação brasileira. São Paulo: Fapesp; Fundap. Brasília: Ipea, 2003. 245 p.

PRADO, Sergio. Distribuição intergovernamental de recursos na federação brasileira. In: REZENDE, F.; OLIVEIRA, F. (Orgs.). Descentralização e federalismo fiscal no Brasil: desafios da reforma tributária. Rio de Janeiro: Konrad Adenauer, 2003. p. 41-125.

PRADO, Sérgio; CAVALCANTI, Carlos Eduardo G. A guerra fiscal no Brasil. São 
Paulo: FUNDAP/ FAPESP; Brasília: Ipea, 2000. 146 p.

REZENDE, Fernando; AFONSO, José Roberto Rodrigues. A federação brasileira: fatos, desafios e perspectivas, dezembro de 2001, 71 p. Disponível em: $<$ www.federativo.bndes.gov.br/bf_bancos/ estudos/e0002426.pdf>. Acesso em: jul. 2008.

REZENDE, Fernando; CUNHA, Armando. Contribuintes e cidadãos: compreendendo o orçamento federal. Rio de Janeiro: Editora FGV, 2002. 152 p.

SERRA, José; AFONSO, José Roberto Rodrigues. O federalismo fiscal à brasileira: algumas reflexões, dezembro de 2001, 29 p. Disponível em: <www.federativo.bndes. gov.br/bf_bancos/estudos/e0001793.pdf> Acesso em: jul. 2008.
SOUZA, Celina. Governos e sociedades locais em contextos de desigualdades e de descentralização. Ciência \& Saúde Coletiva, Rio de Janeiro, v. 7, n. 3, p. 431-442, 2002.

UGÁ, Maria Alicia; MARQUES, Rosa Maria. O financiamento do SUS: trajetória, contexto e constrangimentos. In: LIMA, Nísia Trindade et al. (Orgs.). Saúde e democracia: história e perspectivas do SUS. Rio de Janeiro: Fiocruz, 2005. p. 193-233.

VARSANO, Ricardo. A evolução do sistema tributário brasileiro ao longo do século: anotações e reflexões para futuras reformas. Brasília: Ipea, 1996. Texto para Discussão n.405.

WATTS, Ronald L. Comparing federal systems in the 1990s. Ontario: Institute of Intergovernmental Relations, 1996. 126 p. 
